\title{
Incorporating equality considerations into measures of public service output
}

\section{SUMMARY}

The UK Centre for Measurement of Government Activity was launched in 2005 to improve measures of public service output. This article discusses how distributional weights may be used to incorporate equality considerations into these measures. It also presents the arguments for and against making this type of adjustment.

\section{or decades, economists have \\ - debated the use of distributional weights in cost-benefit analysis.}

This article will broaden the debate to include measures of public service output. But first, what is meant by equality? There is no universally agreed definition but, loosely, equality is the idea of people getting the same, or being treated the same, in some respect. Writers have tried to clarify this concept by posing two questions:

- Equality between whom?

- Equality of what?

\section{Equality between whom?}

'Fairness and opportunity of all' is the subject of government policy, illustrated by Public Service Agreements (PSA) 8 to 17. PSA 15 aims to Address the disadvantage that households experience because of their gender, race, disability, age, sexual orientation, religion or belief.' This is horizontal equity - the equal treatment of groups identified by a common characteristic. Government policy is less explicit on vertical equity - the relative treatment of rich and poor.

\section{Equality of what?}

The Cabinet Office's Equalities Review (Cabinet Office 2007) highlighted several types of equality:

- Equality of process: ensuring that people are treated in the same manner in any given situation.
This idea underpins the right to a fair trial or the right of children to an education, for example

- Equality of worth: according each individual equal respect - a concept that lies behind giving every citizen the right to vote

- Equality of outcome: sometimes interpreted as aiming for everyone to have, for instance, equal amounts of income or wealth, or the same educational opportunities

- Equality of opportunity: a term that is understood in different ways. Some interpret it to mean that outcomes should depend only on an individual's talents and the efforts they make. Others argue that equality of opportunity is about ensuring that those circumstances beyond an individual's control should not undermine the opportunity an individual has to thrive. For example, being born into a family with a low income should not affect the opportunities available to an individual

This article concentrates on equality of outcome as, in principle, this is the easiest to measure.

\section{Weighting output}

One way of incorporating equality considerations into measures of public service output is to attach weight to the output according to who benefits from it, so that the same unit of output is worth more, in some sense, if it benefits poor rather than 
rich individuals, so reducing inequality. There is a precedent for making this type of adjustment. HM Treasury's Green Book (HM Treasury 2003), which provides guidance on the economic assessment of spending and investment, states:

In principle, each monetary cost and benefit should be weighted according to the relative prosperity of those receiving the benefit or bearing the cost... If appraisers decide not to use distributional weights to make an explicit adjustment, this decision must be fully justified.

\section{Deriving the weights}

Welfare economics provides a framework for deriving these weights. Assuming that society's welfare $(W)$ depends upon the income of the households that make up that society $\left(Y_{h}\right)$, then society's welfare is given by $W=W\left(Y_{1}, Y_{2}, \ldots, Y_{H}\right)$. Defining $W_{0}$ as the original welfare of society and $W_{1}$ as society's welfare with an additional unit of public service output, then the change in society's welfare is:

$\Delta W=W_{1}-W_{0}=\sum_{h} \omega_{h} \Delta Y_{h}$

where $\Delta Y_{h}$ is the change in the income of household $h$ due to the change in public service output and $\omega_{h}$ is the weight attached to the change in the income of household $h$. These weights provide a method for formally incorporating concepts of fairness into economic analysis. In economic terms, the weights reflect how much society values a marginal change in the income of an individual household. In this article, the concepts are illustrated in terms of income but they could also have been illustrated in terms of other outcomes, such as consumption.

So, adjusting measures of public service output for equality considerations involves:

- establishing the impact of the public service output on the income of individual households, ${ }^{1}$ that is, obtain $\Delta Y_{h}$, and

- aggregating the impacts into a measure of overall welfare, that is, derive $\omega_{h}$

\section{Obtaining public service output and} household income

The impact of the public service output on the income of individual households can be estimated using benefit incidence analysis. This technique involves allocating per unit public subsidies (for example, expenditure per student for the education sector) according to utilisation rates of public services.

This approach has several weaknesses. One is the difficulty in calculating unit costs. While visits to the doctor or attendances at school can be defined on a unit of service basis, services such as the physical infrastructure (overhead-type services) are more difficult to break down. A second weakness is the use of 'average' participation rates to infer the distributional impact of changes in public spending. The inferences drawn could be wrong if programme participation is nonhomogenous or where the composition of participants varies with the size of the programme. This approach relies on data for utilisation of public services being sufficiently disaggregated.

Benefit incidence analysis focuses on changes in income rather than welfare or utility. How these changes in income translate into changes in wellbeing depends on several factors. For example, a household that contains children is likely to need more resources to achieve the same standard of living as a household where there are no children, other things being equal. The change in wellbeing can be partially captured using an 'equivalence scale' that adjusts household income to account for variations in household size and composition. The choice of scale on which it is used can lead to slightly differing results and has implications for the analysis.

How resources are shared within households is also a factor that affects analysis. For example, suppose a household has two individuals, one who has paid employment and is relatively well-paid, while the other does not have paid employment. Looking at the distribution of income across individuals would show the earner near the top of the income distribution, while the non-earner would be near the bottom. In contrast, the distribution of household incomes would show this household around the middle. The most common approach is to assume pooling or equal sharing of income.

\section{Obtaining welfare weights}

Distributional weights can be derived using the concept of a social welfare function (Samuelson 1947). This function describes how well off society is, given different allocations of resources to its members. In this framework, the weight attached to the change in income of household $\omega_{h}$ has three components:
- The size of the household

- How equivalised income leads to changes in nominal income $Y_{h}$, and

- The social marginal utility or welfare weight; this component models society's aversion to inequality

\section{Inequality aversion}

The use of welfare weights can be illustrated using a form of the social welfare function proposed by Atkinson (1970) that has been used frequently in the literature:

$$
\begin{aligned}
& \mathrm{W}\left(\mathrm{u}_{1}(.), \mathrm{u}_{2}(.), \ldots, \mathrm{u}_{\mathrm{n}}(.)\right)=\sum_{h=1}^{n} w\left(u_{h}\right) \\
& =\sum_{h=1}^{n} \frac{u_{h}^{1-\gamma}}{(1-\gamma)} \text { for } \gamma \neq 1 \text { and } \log \left(u_{h}\right) \text { for } \gamma=1
\end{aligned}
$$

The parameter $\gamma$ describes how much a household's welfare weight decreases as its income increases. The higher $\gamma$ is, the faster the rate of proportional decline in welfare weight to proportional decline in welfare. Thus, $\gamma$ describes the strength of society's desire for equality of incomes compared with uniformly higher incomes for all. For example:

- $\gamma=0$ gives the utilitarian social welfare function where social welfare is the sum of household utilities, with the utility of each household given equal weighting

- $\gamma=\infty$ results in the Rawlsian social welfare function which assumes that society's welfare is the utility of the least well-off household (Rawls 1972)

- $0 \leq \gamma \leq \infty$ describes the situation where society is prepared to redistribute resources from rich to poor even if some of the resources are lost in the process

Cowell and Gardiner (1999) described three justifications for the use of welfare weights.

\section{The individual welfare approach}

This is based on the idea that individuals have diminishing marginal utility of income (or consumption). This means that the effect on the subjective wellbeing of a change in income becomes progressively smaller the higher the initial level of income. If this assumption is correct, then providing an additional $£ 1$ of income to a poor household will have a greater positive impact on the household's wellbeing than providing $\mathfrak{E} 1$ of income to a rich household, other things being equal.

Based on Pearce and Ulph (1995), Cowell and Gardiner (1999) and OXERA (2002), the Green Book states that the available evidence suggests the elasticity of the marginal utility of income is around one. 
This implies that an increment to income occurring when income is, say, $£ 50,000$ is half as valuable as if it occurs when income is $£ 25,000$. This estimate is supported by other studies, for example, Evans (2005) and Layard et al (2007).

\section{The externalities approach}

This approach suggests that the wellbeing of households is likely to depend on the income of other households as well as their own. In technical terms, an externality occurs when the production or consumption decisions of one agent have an impact on the objective function of another agent in an unintended way, and when no payment is made by the generator of the impact to the affected party. For example, vaccinating one person means that that individual is less likely to get the illness they have been vaccinated against (the private benefit) and other people also gain because they are now less likely to contract the illness (the external benefit).

A 'caring' externality occurs when households receive benefit from knowing that other people are receiving medical treatment. Knowing that someone is in pain because they cannot afford medical treatment makes other people in society feel bad - it causes 'negative utility'. This has led several authors to suggest that some public services, notably healthcare, have different ethical considerations than other goods and services and should be distributed according to non-market principles. An aversion to inequality aversion in this case is determined by the marginal utility of the externality.

\section{Incomplete information}

The final approach suggests that households have incomplete information about their future circumstances and may be willing to pool some of their future income to reduce the risks they face. In this approach, households 'care' about inequality because there is a risk of them being in the lower part of the distribution. How much they care depends on how risk averse they are (Dahlby 1987).

\section{Empirical evidence on inequality aversion}

As inequality aversion cannot be directly measured, earlier work has mainly utilised a questionnaire approach for quantifying the level of inequality aversion. Perhaps the most well-known way of contrasting efficiency and equity is the 'leaky bucket' idea due to Okun (1975). An amount of money is transferred from the rich to the poor, but a certain fraction of it is lost when doing so, for instance, because of administrative costs. The extent of the loss, or leakage, society can accept determines the level of inequality aversion. The higher the tolerable leakage is, the more society is averse to inequality. Following this method, Amiel et al (1999) conducted experiments for groups of students from two different countries. They found that inequality aversion could be measured in a reasonably precise way. They estimated that median inequality aversion was between 0.1 and 0.2 , much lower than values typically used by economists in simulations.

An alternative way of formalising the efficiency-equity trade-off is to present a hypothetical situation in which respondents have a choice between different income distributions. In one of the societies, the mean income is low and the income dispersion small; in the other, the mean income is higher but the income distribution is more dispersed. Using this approach in an experiment with Swedish students, Carlsson, Daruvala and Johansson-Stenman (2005) found that the median inequality aversion lies between 1 and 2 . Their estimate was ten times larger than the estimate deduced by Amiel et al (1999).

Most of the evidence in this area is obtained from experiments involving university students. It is unclear how well this evidence can be generalised for wider populations. Even within experimental studies, it has been shown that the composition of the participants (for example, economics students compared with students from other disciplines) can have large effects on the estimates of inequality aversion (Engelman and Strobel 2004, Fehr et al 2006). The experiments also rely on hypothetical situations, where the sums of money are unrelated to any realworld situation in which the respondents are familiar.

\section{Applying discount factors}

The full benefit of a public service may not materialise until months or even years after the provision of the service. For example, the increased earnings arising from additional years of schooling would be realised throughout an individual's lifetime. Similarly, some public services have important intergenerational impacts. This can be incorporated into this analysis by applying a discount factor to the output, which varies according to when the benefit of the public service is realised. This discount factor captures several ideas.
First, individuals prefer to have things such as income now rather than in the future (pure time preference).

Second, there is a risk that there will be some event so devastating that all returns from policies, programmes or projects are eliminated, or at least radically and unpredictably altered. Examples are technological advancements that lead to premature obsolescence, natural disasters or major wars. The scale of this risk is, by its nature, hard to quantify.

Third, because income and consumption tend to grow over time, additional income in the future will have less value. This is a reflection of the diminishing marginal utility of income idea presented above. HM Treasury's Green Book uses the empirical evidence on these factors to calculate a discount rate of 3.5 per cent. However, it also recommends that, where a project has long-term costs or benefits (beyond 30 years), a lower discount rate should be used to reflect the uncertainty about the future.

\section{Is the adjustment appropriate?}

Having set out how an adjustment to measures of public service output might be made, it is useful to consider some of the issues about whether making this adjustment is appropriate.

The Atkinson Review (Atkinson 2005) noted that:

[Governments] are concerned with distribution as well as with totals. They are concerned with rights and procedural justice, as well as with outcomes. Equity and fairness have value for governments, but are not captured in the National Accounts. For these reasons alone, there is no reason to expect government policy to be directed solely at maximising national output; nor, conversely, should the output measure be determined solely by the policy objectives.

Thus, the main argument for making this type of adjustment is that equality is valued by governments and society and so the UK Centre for Measurement of Government Activity (UKCeMGA) should incorporate this into measurements of public service output.

One of the main arguments against making this type adjustment is that it is inconsistent with National Accounts methodology, where transactions are valued independently of who engages in them. Principle A from the Atkinson Review is that, 'the measurement of government nonmarket output should, as far as possible, 
follow a procedure parallel to that adopted in the National Accounts for market output.'

As implicitly illustrated above, the implementation of an equality adjustment requires a number of judgements about the functional form of individual and societal welfare functions. The counter argument is that the use of equal weights for everybody, implicit in current methods, is itself a value judgement.

Making this type of adjustment relies on having sufficiently disaggregated data which enables us to distinguish between individuals or households of particular types. As HM Treasury’s Green Book acknowledges:

'...this information is unlikely to be available at acceptable cost for many applications. The decision on whether an explicit adjustment is warranted should be informed by the: scale of the impact associated with a particular project or proposal; likely robustness of any calculation of distributional impacts; and the type of project being assessed.'

\section{Conclusions}

This article has suggested that because public bodies and private companies fulfilling public functions are required to promote equality, this should be taken into account when measuring their output. The inconsistency with National Accounts means that an appropriate way ahead is to try to introduce the adjustment in measures of output that do not feed into National Accounts but are used in UKCeMGA productivity articles or satellite accounts.

To implement the methods outlined in this article, UKCeMGA needs to decide on what perspective of equality the adjustment will reflect. Will an adjustment be made for horizontal equity (the treatment of groups identified by race, disability or gender, or vertical equity - the relative treatment of rich and poor)? The latter would be easier to implement, as estimates of many of the relevant parameters identified in this article have already been made. In contrast, if the adjustment is made to reflect horizontal equity, there is a need to produce new parameter estimates, for example, on society's aversion to inequality across groups.

The next question is whether to apply the adjustment to costs or to valuations. To apply the weights to costs, UKCeMGA needs to identify how the cost of producing the marginal output is distributed across the equality dimension chosen and then weight it. For example, if the health service performed more operations, the cost of an operation would be adjusted depending on who receives it.

Alternatively, to move to an output measure, UKCeMGA needs to identify how the benefit of the marginal unit of public service output is distributed across the equality dimension chosen and over time. For example, assuming, for simplicity, that the output of the public education system is to raise productivity and earnings and that the increase in earnings is received for several years into the future, then UKCeMGA would need to calculate the increase in earnings for each category of the equality dimension considered and then discount the earnings. To consider a wider range of outputs would require the development of methods of measuring these outputs, using a common scale. For example, if 'staying safe' at school is considered an output of the public education system, UKCeMGA would need to estimate the monetary value of this so that it could be adjusted in the same way as the increase in earnings.

As with any adjustment that has a subjective dimension, sensitivity analysis should be used to investigate how measures of output and productivity change are affected by using different functional forms and parameters.

\section{Notes}

1 For simplicity, this article discusses concepts in terms of households but the arguments also apply, for example, to individuals, groups and regions.

\section{CONTACT}

(지elmr@ons.gsi.gov.uk

\section{REFERENCES}

Amiel Y, Creedy J and Hurn S (1999)

'Measuring attitudes towards inequality', Scandinavian Journal of Economics 101, pp 83-96.

Atkinson A B (1970) 'On the measurement of inequality', Journal of Economic Theory, 2, pp 244-63.
Atkinson A B (2005) 'Atkinson Review: Final Report. Measurement of Government Output and Productivity for the National Accounts', Palgrave Macmillan.

Cabinet Office (2007) Fairness and Freedom: The Final Report of the Equalities Review.

Carlsson F, Daruvala D and JohanssonStenman O (2005) 'Are people inequalityaverse or just risk averse?', Economica, 72, pp 375-96.

Cowell F A and Gardiner K A (1999) 'Welfare Weights', OFT Economic Research Paper no. 202, Office of Fair Trading: London.

Dahlby B (1987) 'Interpreting inequality measures in a Harsanyi framework', Theory and Decision, 22, pp 187-202.

Engelman D and Strobel M (2004) 'Inequality aversion, efficiency, and Maximin preferences in simple distribution experiments', American Economic Review, 94, pp 857-69.

Evans D (2005) 'The elasticity of marginal utility of consumption, estimates for twenty OECD countries', Fiscal Studies, 26, pp 197-224.

Fehr E, Naef M and Schmidt K (2006) 'Inequality aversion, efficiency, and Maximin preferences in simple distribution experiments: Comment', American Economic Review 96, pp 1912-17.

Layard R, Mayraz G and Nickell S (2007) 'The marginal utility of income', Working paper, London School of Economics.

HM Treasury (2003) Green Book, Appraisal and Evaluation in Central Government.

Okun A (1975) Equality and efficiency: The big trade-off, Brookings Institution: Washington D.C.

OXERA (2002) 'A Social Time Preference Rate for Use in Long-Term Discounting', A report for ODPM, DfT and Defra.

Pearce D and Ulph D (1995) 'A Social Discount Rate For The United Kingdom', CSERGE Working Paper no. 95-01, School of Environmental Studies, University of East Anglia, Norwich.

Rawls J (1972) A Theory of Justice, Clarendon Press, Oxford.

Samuelson P A (1947) Foundations of Economic Analysis, Harvard University Press. 